\title{
Análise espacial da qualidade microbiológica das águas do rio Piancó no trecho Co- remas-Pombal-PB
}

\section{Spatial analysis of the microbiological water quality of the in Piancó River, section Coremas-Pombal-PB}

\author{
Sanduel Oliveira de Andrade ${ }^{1}$, Diego Lima Crispim ${ }^{2}$, Maria Aparecida de Sousa ${ }^{3}$, Alan Del Carlos Gomes Chaves ${ }^{4}$, Patrício \\ Borges Maracajá ${ }^{5}$.
}

Resumo: A água está intrinsicamente relacionada ao desenvolvimento das grandes civilizações, desde o desenvolvimento da agricultura até os modernos processos industriais. É um recurso natural essencial, seja pela importância como componente bioquímico humano, animal e vegetal, bem como, um aspecto relevante nos valores sociais, culturais e econômicos. O presente trabalho tem por objetivo analisar espacialmente a qualidade microbiológica da água de um dos principais rios da região do semiárido paraibano, o Rio Piancó, no trecho localizado entre os municípios de Coremas e Pombal - PB. Tanto as características físicas, químicas como as biológicas da água podem sofrer modificações. O trabalho foi realizado em um trecho do Rio Piancó, compreendendo as cidades de Coremas e Pombal-PB no período de 18 de junho a 20 de dezembro de 2012 . Foram coletadas amostras de água em 04 pontos previamente definidos e analisados em laboratório. Os dados deixaram evidente que o Rio Piancó está sofrendo impacto em sua qualidade, em maior parte pelo deságue de efluentes domésticos, fato constatado pela alta concentração de coliformes encontrada, sendo um fator de risco à saúde humana. Foi contatada a presença de bactéria Escherichia coli e Vibrio cholerae que podem causar sérias doenças.

Palavras-chave: Geoprocessamento, preservação ambiental, coliformes

\begin{abstract}
Water is intrinsically related to the development of the great civilizations, from the development of agriculture to modern industrial processes. It is an essential natural resource, either by biochemical importance as human, animal and plant component as well as a relevant aspect of the social, cultural and economic values. This work aims to spatially analyze the microbiological water quality of one of the biggest rivers of Paraiba semiarid region, Piancó River, located on the stretch between the towns of Coremas and Pombal state of Paraiba. Both the physical and chemical characteristics as biological water may change. The work was carried out on a stretch of the River Piancó, comprising the towns of Coremas and Pombal, state of Paraiba, from 18 June to 20 December 2012. Water samples were collected from 04 points previously defined and analyzed in the laboratory. The data make it clear that the river is suffering Piancó impact on their quality, mostly by domestic effluent outflowing, a fact confirmed by the high concentration of coliforms found. The results indicate the water of said river as a risk factor for human health, such as Escherichia coli and Vibrio cholerae bacterium that can cause serious illness.
\end{abstract}

Key words: GIS, environmental preservation, coliforms.

\footnotetext{
*Autor para correspondência

Recebido para publicação em 08/03/2015; aprovado em 20/04/2015

${ }^{1}$ Engenheiro Agrônomo, Universidade Federal de Campina Grande - UFCG; Especialista em Geoprocessamento, Faculdades Integradas de Patos - FIP; Especializando em Educação Ambiental e Geografia do Semiárido, Instituto Federal do Rio Grande do Norte - IFRN; Mestrando em Sistemas Agroindustriais, Universidade Federal de Campina Grande - UFCG. Pombal-PB; Fone: 83-991096115, E-mail: sanduelandrade@ hotmail.com.

${ }^{2}$ Engenheiro Ambiental, Universidade Federal de Campina Grande - UFCG; Especializando em Educação Ambiental e Geografia do Semiárido, Instituto Federal do Rio Grande do Norte - IFRN; Mestrando em Sistemas Agroindustriais, Universidade Federal de Campina Grande - UFCG. Pombal-PB; Fone: 83999203778, E-mail: diegolc_85@hotmail.com.

${ }^{3}$ Engenheira Agrônoma, Universidade Federal de Campina Grande - UFCG. Pombal-PB; Fone: 83-999296752, E-mail: cidaufcg@ hotmail.com.

${ }^{4}$ Mestre em Sistemas Agroindustriais; CCTA/UFCG, Telefone: (83) 96589908; Campus de Pombal-PB, E-mail: alandcgc@ hotmail.com

${ }^{5}$ Engenheiro Agrônomo, Doutor em Agronomia - Professor da Universidade Federal de Campina Grande (UFCG/CCTA/UAGRA) E-mail: patrício@ufcg.edu.br
} 


\section{INTRODUÇÃO}

A água é um recurso natural essencial, seja pela importância como componente bioquímico humano, animal e vegetal, bem como, um aspecto relevante nos valores sociais, culturais e econômicos. Entretanto pode constatar que a água doce, de boa qualidade, está se tornando cada vez mais escassa, devido principalmente a contaminações dos mananciais existentes.

O Brasil é um país privilegiado no tocante a quantidade de água, possuindo cerca de $12 \%$ da água doce do planeta, porém possui uma distribuição uniforme, concentrando grande parte na região norte do país, cerca de $81 \%$, ficando menos de $20 \%$ para as demais regiões. Na região Nordeste, a escassez de chuvas agrava esta problemática, apresentando reservas insuficientes de água em seus mananciais (ANDREU, 2012).

A qualidade da água não significa necessariamente a pureza da mesma, porém diz respeito a suas características desejadas para determinados usos. Tanto as características físicas, químicas como as biológicas da água podem sofrer modificações. Na maioria dos casos essa modificação é oriunda da poluição, que pode ter diversas origens. Tal problemática acarreta sérios prejuízos econômicos para a região, como o custo de aquisição e tratamento da água (LIMA, 2013).

De acordo com Toledo \& Nicolella (2004), para definir um parâmetro de qualidade de água superficial, se faz necessário o uso de métodos básicos e que nos dão informações precisas e de fácil interpretação. Diante disso, o uso de índices de qualidade de água é uma tentativa que grande parte dos programas de monitoramento de águas superficiais prevê como forma de acompanhamento, através de informações sucintas, a possível comprometimento dos recursos hídricos ao longo da bacia hidrográfica ou ao longo do tempo.

Diante dessa problemática o presente artigo visa analisar espacialmente a qualidade microbiológica da água de um dos principais rios da região do semiárido paraibano, o Rio Piancó, no trecho perenizado pela barragem Estevão Marinho, entre os municípios de Coremas e Pombal - PB.

\section{MATERIAL E MÉTODOS}

O trabalho foi realizado em um trecho perenizado do Rio Piancó, compreendendo as cidades de Coremas e Pombal-PB. Na cidade de Pombal-PB, o referido rio une-se com outro denominado Rio Piranhas, passando a ser chamado como tal. Foi conduzido no período de 18 de junho a 20 de dezembro de 2012. O município de Pombal-PB situa-se a $06^{\circ} 45^{\prime}$ de latitude sul e $37^{\circ} 48^{\prime}$ de longitude oeste e uma altitude de $175 \mathrm{~m}$.

O município está inserido na unidade geoambiental da Depressão Sertaneja, que representa a paisagem típica do semiárido nordestino, caracterizada por uma superfície de pediplanação bastante monótona, relevo predominantemente suave-ondulado, cortada por vales estreitos, com vertentes dissecadas. Elevações residuais, cristas e/ou outeiros pontuam a linha do horizonte. Esses relevos isolados testemunham os ciclos intensos de erosão que atingiram grande parte do sertão nordestino (BELTRÃO, 2005). O clima é o Aw', segundo a classificação de Köppen, semiárido, com chuvas de verão e outono e a precipitação pluviométrica média anual de 800 $\mathrm{mm}$, com variabilidade interanual, sendo os meses de fevereiro, março e abril os que mais chovem, concentrando 60 a $80 \%$ do total da precipitação anual. Possui temperaturas médias mensais variando de 23,40 a $27,90^{\circ} \mathrm{C}$; com máximas mensais de $35,70^{\circ} \mathrm{C}$ em dezembro, e mínimas de $19,30^{\circ} \mathrm{C}$, em julho e agosto (MOURA, 2007).

As amostras de águas foram coletadas ao longo do Rio Piancó em 4 diferentes pontos (Figura 1). O ponto 1 $\left(07^{\circ} 01^{\prime} 19,00^{\prime}\right.$ 'S e $\left.37^{\circ} 56^{\prime} 54,45^{\prime}, \mathrm{W}\right)$ corresponde à proximidade da nascente da parte perenizada do Rio Piancó, na barragem do açude Estevão Marinho, localizada no município de Coremas-PB. O ponto 2 (06 50 '29.00'’S e $37^{\circ} 50^{\prime} 34.1^{\prime \prime}$ 'W) localizará no local popularmente conhecido por "Ponte das Flores", no Sítio Flores, município de Pombal-PB. O ponto 3 $\left(6^{\circ} 48^{\prime} 21,55^{\prime}\right.$ 'S e $\left.37^{\circ} 49^{\prime} 29,00^{\prime \prime} \mathrm{W}\right)$ corresponde à localidade conhecida por "Ponte do Trem", zona rural do município de Pombal-PB. O ponto 4 (6 $6^{\circ} 43^{\prime} 34,26^{\prime}$ 'S e $\left.37^{\circ} 47^{\prime} 51,27^{\prime \prime} \mathrm{W}\right)$ localizada as margens da BR 230 (Rodovia Transamazônica) conhecido como "Ponte do Areial", no bairro Jardim Rogério, município de Pombal-PB.

Figura 1. Localização da área de estudo.

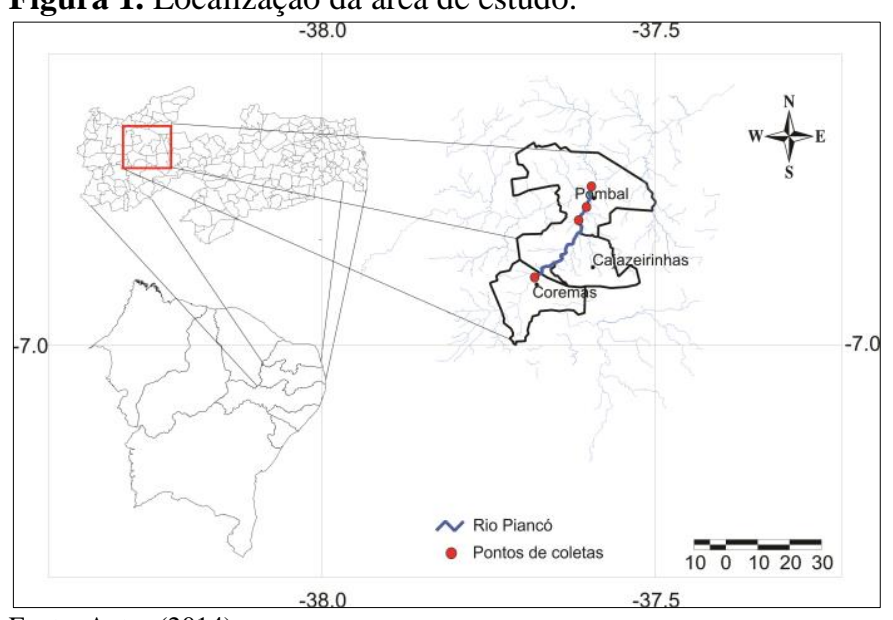

Fonte: Autor (2014)

As amostras d'água foram coletadas, utilizando recipientes de vidro com tampa devidamente esterilizado em autoclave e com plástico filme protetor. As amostras foram acondicionadas em uma caixa de isopor com gelo, para conservar suas características microbiológicas, e encaminhadas para o Laboratório de Análises de Água do Centro Vocacional Tecnológico (CVT), administrado pela Universidade Federal de Campina Grande (UFCG), campus de Pombal $\mathrm{PB}$, sendo entregue em menos de 24 horas após a coleta.

Adotou-se como metodologia para análise dos parâmetros microbiológicos o Manual prático de análise de água da FUNASA (FUNASA, 2009).

Cada amostra de água coletada foi inoculada em série de 3 tubos contendo $10 \mathrm{~mL}$ de caldo Lauryl, Calvo Verde Bile Brilhante (CVBB) e Caldo EC, nos seguintes volumes: $0,1 \mathrm{~mL}, 1 \mathrm{~mL}$ e $10 \mathrm{~mL}$ respectivamente em cada um dos tubos. Os tubos múltiplos com Lauryl e CVBB foram incubados em estufa por $24 \mathrm{~h}$ a $37^{\circ} \mathrm{C}$ e os tubos contendo meio EC incubados em banho-maria a $44,5^{\circ} \mathrm{C}$ durante 24 horas.

De cada tubo positivo, oriundos do Caldo EC, foram transferidas amostras com alça de níquel-cromo para placas 
com Ágar EMB. Estas permaneceram incubadas por 24 horas a $35^{\circ} \mathrm{C}$, para verificação dos tipos de colônias que se desenvolveram nestas placas (Figura 2).

Figura 2. Repicagem das amostras positivas do Caldo EC para placas com Ágar BEM

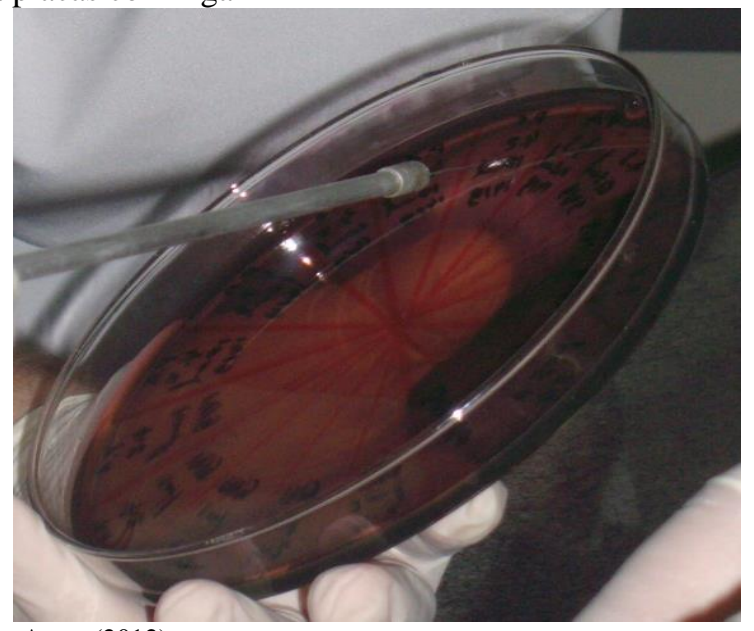

Fonte: Autor (2012)

No tocante a análise espacial, no desenvolvimento deste trabalho utilizou-se de um banco de dados relacional na categoria cadastral, integrante do Spring 5.2.5, para a criação e estruturação do SIG-Rio Piancó. Nele foram inclusas informações espaciais e alfanuméricas, dispostas em diferentes entidades. No banco de dado desenvolvido foram atribuídos relacionamentos entre suas diversas entidades com objetivo de tornar a estrutura mais próxima possível da realidade do curso de água.

\section{RESULTADOS E DISCUSSÃO}

O Número Mais Provável (NMP) é a estimativa da densidade média de bactérias do grupo coliforme em uma amostra, calculada a partir da combinação de resultados positivos e negativos, obtidos mediante a técnica de tubos múltiplos. O NMP de coliformes é expresso como a densidade média de bactérias contidas em 100 mililitros de amostra.

Para o enquadramento das águas de rio foram utilizados os parâmetros de classificação estabelecidos pela Resolução CONAMA no 357/2005 como uso de recreação de contato secundário e que não deverá ser excedido um limite de 2500 coliformes termotolerantes por 100 mililitros (BRASIL, 2005).

A concentração de coliformes termotolerantes foi utilizada como indicador de poluição e também da ação antrópica, ao qual tem refletido no desequilíbrio dos ecossistemas aquáticos estudados, desequilíbrio este causado principalmente pelo efeito do lançamento direto de esgotos e resíduos domésticos sem seu devido tratamento (TERRA et al., 2008). Os coliformes termotolerantes, por si só, não são considerados patogênicos, entretanto, sua detecção na amostra é um indicador da existência potencial de agentes patogênicos, como por exemplo, o vírus da hepatite e a bactérias a Salmonella (CETESB, 2010).

No ponto 1, nascente perenizada do Rio Piancó, os resultados observados demostram em os coliformes totais ficou entre 48 a $170 \mathrm{NMP} / 100 \mathrm{ml}$ (Tabela 01), fazendo uma média de 97 NMP/100 ml. Macedo (2003) afirma que a pre- sença de coliformes em água eleva o risco da presença de microrganismos patogênicos, consequentemente, se tornando veículo para transmissão de vários tipos de doenças. Entretanto, no tocante ao parâmetro microbiológico verificou-se que estão dentro dos limites estabelecidos pela resolução CONAMA no 357/2005, para corpos de água da classe II, ficando consideravelmente abaixo do limite máximo permitido é de $\leq$ $1000 \mathrm{NMP} / 100 \mathrm{ml}$, sendo encontrado neste ponto em média de $10 \mathrm{NMP} / 100 \mathrm{ml}$ (Tabela 1).

Tabela 01. Resultado das análises obtidas próximo a nascente perenizada do Rio Piancó em Coremas-PB (Ponto 1)

\begin{tabular}{l|l|l|l}
\hline \multirow{2}{*}{ Parâmetros } & \multicolumn{3}{|c}{ Coletas } \\
\cline { 2 - 4 } & \multicolumn{1}{|c}{$\mathbf{1}$} & \multicolumn{1}{c}{$\mathbf{2}$} & \multicolumn{1}{|c}{} \\
\hline Teste presuntivo & $>1600$ & $>1600$ & $>1600$ \\
\hline Coliformes Totais & 170 & 73 & 48 \\
\hline Coliformes Termotolerantes & 20 & 6 & 3 \\
\hline
\end{tabular}

Fonte: Autor (2012).

No Ponto 2, nas proximidades da ponte do Sítio Flores, já no município de Pombal-PB, foi verificado um aumento na presença dos coliformes termotolerantes, porém permanecendo dentro dos parâmetros exigidos pela resolução $\mathrm{CO}$ NAMA no 357/2005 (Tabela 2). Este local também é usado para recreação, por ser um local de fácil acesso e não possui elevada profundidade na maior parte do ano. Scandelai et al., (2012) destaca que as águas recreacionais podem conter microrganismos patogênicos de vida livre, podendo causar infecções gastrointestinais ou respiratórias

Tabela 02. Resultado das análises obtidas nas proximidades da ponte do Sítio Flores, município de Pombal-PB (Ponto 2)

\begin{tabular}{l|l|l|l}
\hline \multirow{2}{*}{ Parâmetros } & \multicolumn{3}{|c}{ Coletas } \\
\cline { 2 - 4 } & $\mathbf{1}$ & $\mathbf{2}$ & $\mathbf{3}$ \\
\hline Teste presuntivo & $>1600$ & $>1600$ & $>1600$ \\
\hline Coliformes Totais & $>1600$ & 1236 & $>1600$ \\
\hline Coliformes Termotolerantes & 567 & 140 & 437 \\
\hline
\end{tabular}
Fonte: Autor (2012).

No ponto 3, nas proximidades da Ponte do Trem, os resultados foram próximos aos resultados obtidos no ponto 2 , consequentemente permanecendo dentro dos parâmetros exigidos pela resolução CONAMA no 357/2005 (Tabela 3).

Tabela 03. Resultado das análises obtidas nas proximidades da Ponte do Trem, município de Pombal-PB (Ponto 3)

\begin{tabular}{l|l|l|l}
\hline \multirow{2}{*}{ Parâmetros } & \multicolumn{3}{|c}{ Coletas } \\
\cline { 2 - 4 } & \multicolumn{1}{|c}{$\mathbf{1}$} & \multicolumn{1}{c}{$\mathbf{2}$} & \multicolumn{1}{|c}{$\mathbf{3}$} \\
\hline Teste presuntivo & $>1600$ & $>1600$ & 1373 \\
\hline Coliformes Totais & 1340 & 1373 & 953 \\
\hline Coliformes Termotolerantes & 500 & 130 & 320 \\
\hline
\end{tabular}

Fonte: Autor (2012).

Já no ponto 4, nas proximidades da Ponte ao Areial, há uma elevação considerável nos parâmetros microbiológicos, ficando em desconformidade com o proposto pela Resolução CONAMA 357/05, no tocante aos coliformes termotolerantes, foi verificado uma média elevada, de 1316 NMP/100 
mL (Tabela 4), acima do aceitável pela legislação. Este ponto está localizado a jusante da área urbana de cidade de Pombal$\mathrm{PB}$ e as elevadas concentrações deste parâmetro podem ser atribuídas ao despejo de efluentes doméstico, sem deu devido tratamento, no corpo hídrico, o que é preocupante do ponto de vista da saúde pública (Figura 3).

Neto et al (2002) também destaca que os efluentes oriundos das residências e estabelecimentos comercial dos centros urbanos e rurais são responsáveis pelo aumento das concentrações de coliformes em água e ainda salienta que esta problemática é agravada pela presença de banhistas que utilizam o rio como fonte de recreação.

Tabela 04. Resultado das análises obtidas nas proximidades da Ponte do Areial, município de Pombal-PB (Ponto 4)

\begin{tabular}{l|l|c|c}
\hline \multirow{2}{*}{ Parâmetros } & \multicolumn{3}{|c}{ Coletas } \\
\cline { 2 - 4 } & $\mathbf{1}$ & $\mathbf{2}$ & $\mathbf{3}$ \\
\hline Teste presuntivo & $>1600$ & $>1600$ & $>1600$ \\
\hline Coliformes Totais & 1373 & $>1600$ & $>1600$ \\
\hline Coliformes Termotolerantes & 730 & $>1600$ & $>1600$ \\
\hline
\end{tabular}

Fonte: Autor (2012).

Figura 3. Lançamento de efluentes urbanos no rio Piancó, município de Pombal-PB

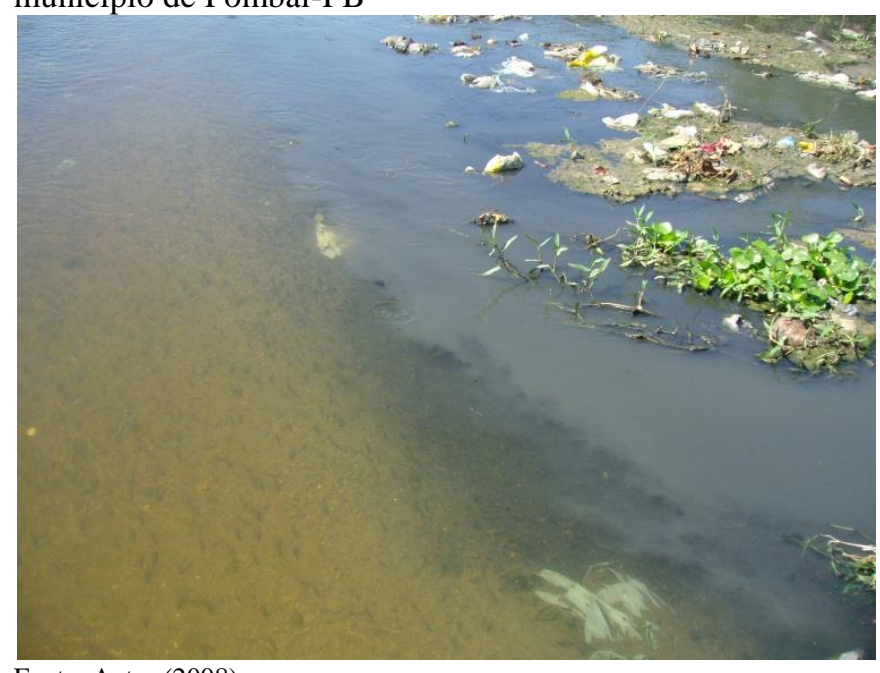

Fonte: Autor (2008).

Conforme Aléssio et al. (2009), este tipo de contaminação pode estar relacionado com a presença de fossas, que através da infiltração, comprometem a qualidade do lençol freático, bem como a problemas na estrutura nas canalizações de esgoto das residências ou ainda o contato direto com fezes humanas ou de animais oriundas do escoamento superficial.

Conforme Melo et al. (1990), as águas que são ricas em matéria orgânica, o número de bactérias é elevado em virtude destas utilizarem este material como fonte de alimento.

Comparando os índices de NMP/100 mL obtidos nas amostras dos quatro pontos, observa-se que há presença de coliformes termotolerantes em todos os pontos. O ponto 1 foi o que apresentou menor expressividade em relação a presença desse grupo de bactérias, com apenas 10 NMP/100 mL. Durante o percurso do rio, o NMP/100 $\mathrm{mL}$ foi se elevando. No ponto 4 , os resultados obtidos demostram que, os efluentes despejado no referido rio, elevaram significativamente os índices de coliformes totais e termotolerantes, tornando a água impropria para o uso (Figura 4). Outro fato de extrema relevância foi a presença de E. coli nos pontos analisados, merecendo destaque o Ponto 04, com concentrações bastante elevadas. A presença de $E$. coli foi constatada pela coloração verde metálica em meio Ágar BEM (Figura 5).

Figura 4. Variação de NMP/100mL das amostras nos quatro pontos estudados.

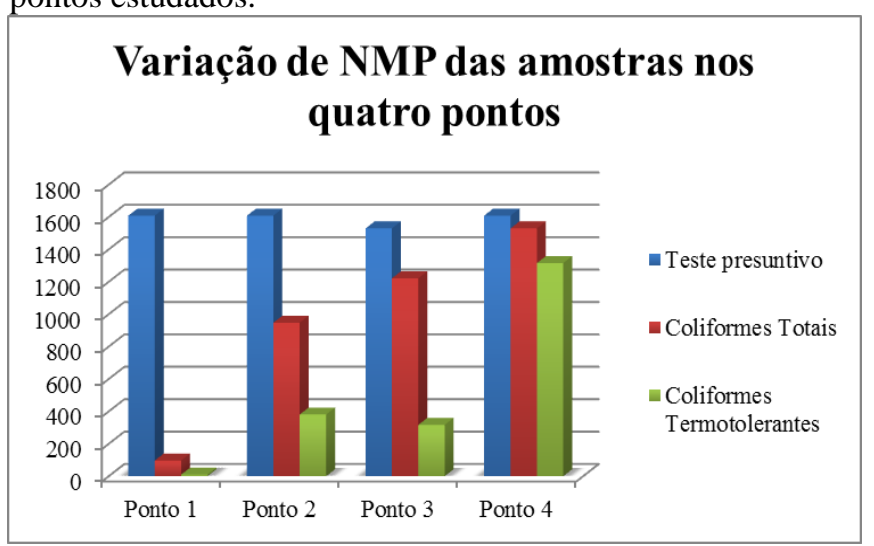

Figura 5. Presença de E. coli nas amostras analisadas.

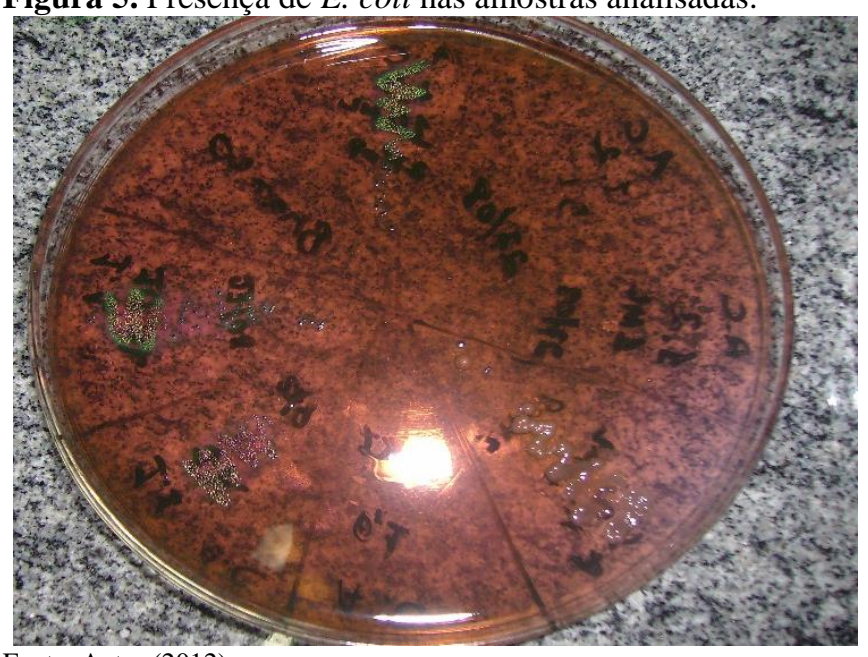

Fonte: Autor (2012)

\section{CONCLUSÕES}

Os dados mostraram que o Rio Piancó está sofrendo impacto em sua qualidade, principalmente através da entrada de esgoto doméstico, fato constatado pela alta concentração de coliformes encontrada. Os resultados obtidos apontam a água do referido rio como um fator de risco à saúde humana, devido aos grupos de microrganismos encontrados, como a bactéria Escherichia coli e Vibrio cholerae que podem causar sérias doenças. Com isso, é necessário o desenvolvimento de ações preventivas com intuito de esclarecer a população local sobre os riscos à saúde que a presença do esgoto doméstico representa e evitar que esgotos clandestinos possam desaguar nas galerias pluviais e, consequentemente, efluir para os corpos hídricos.

\section{REFERÊNCIAS BIBLIOGRÁFICAS}

ALESSIO, C. E, PINTO, F. G. S., MOURA, A. C. Avaliação Microbiológica das Águas das Principais Fontes de Praças e Parques de Cascavel - PR. UNOPAR Cient., Ciênc. Biol. Saúde. n.11, v.2 :41-44, 2009. 
ANDREU, V. Água para as Cidades Brasileiras. Agência Nacional de Águas - ANA. 2012. Disponível em: < http://arquivos.ana.gov.br/imprensa/artigos/20120430_ $\%$ C3\%81gua$\% 20$ para $\% 20$ as $\% 20$ cidades\%20brasileiras_Vers\%C3\% A-

3o\%20enviada\%20para\%20o\%20Trigueiro\%20(2).doc> . Acesso em: 12 jul. 2013.

BELTRÃO, B. A.; MORAIS F.; MASCARENHAS J. C.; MIRANDA J. L. F.; JÚNIOR L. C. S.; MENDES V. A. Projeto Cadastro de Fontes de Abastecimento por Água Subterrânea. Estado da Paraíba. Diagnóstico do Município de Pombal. Ministério de Minas e Energia. Recife, 2005.

BRASIL. Ministério do Meio Ambiente. Resolução $\mathbf{N}^{\mathbf{0}}$ 357, de 17 de março de 2005. Disponível em: <http://www.mma.gov.br/port/conama/res/res05/res3570 5.pdf >. Acesso em: 20 ago. 2013.

CETESB. Companhia de Tecnologia de Saneamento Ambiental. Variáveis de Qualidade das Águas. 2010. Disponível em: <http://www.cetesb.sp.gov.br/agua/aguassuperficiais/109variaveis-de-qualidade-das-aguas>. Acesso em: 25 ago. 2013.

HIRATA, R. C. A. Recursos Hídricos. In: TEIXEIRA W. et al. (Org). Decifrando a terra. São Paulo: Oficina de Textos, 2000. p 421 - 442.

LIMA, M. L. A. de. Uso do geoprocessamento na qualidade de água superficial destinada ao abastecimento humano no Estado de Rondônia. Disponível em: <http://www.agro.unitau.br/serhidro/doc/pdfs/199206.pdf>. Acesso em: 08 mar. 2013.
MACÊDO, J. A. B. de. Métodos laboratoriais de análises físico-químicas e microbiológicas. 2.ed. Belo Horizonte: Conselho Regional de Química, 2003. 450p.

MELO, M.T.D.; SAKER-SAMPAIO, S.; VI EIRA, R.S.H.F. Avaliação da poluição orgânica no estuário do Rio Ceará (Fortaleza- Ceará - Brasil). Caatinga, 7 : 207 - 219, 1990.

MOURA, E. M. Avaliação da disponibilidade hídrica e da demanda hídrica do trecho do rio Piranhas-Açú entre os açudes Coremas-Mãe D'água e Armando Ribeiro Gonçalves. Dissertação (mestrado). Universidade Federal do Rio Grande do Norte. Natal, 2007.

NETO, M. E.; SILVA, W.O. de; RAMEIRO, F.C.; NASCIMENTO, E.S. do; ALVES, A. de S. Análises físicas, químicas e microbiológicas das águas do balneário Veneza na Bacia Hidrográfica do Médio Itapecuru, MA. Arq. Inst. Biol., São Paulo, v.79, n.3, p.397-403, jul./set., 2012.

SCANDELAI, A. P. J.; SOLINA, M. R. F.; SOUZA, A. T. Avaliação da balneabilidade e qualidade da água da represa Laranja-Doce no município de Martinópolis-SP. Colloquium Exactarum, v. 4, n.2, Julho-Agosto. 2012.

TERRA, V.R.; PRATTE-SANTOS, R.; ALIPRANDI, R. B.; BARCELOS, F. F.; AZEVEDO JR, R. R.; BARBIÉRI , R. S. Avaliação microbiológica das águas superficiais do rio Jucu Braço Sul, ES, Brasil. Natureza on line 6 (1): 48-52. 2008. Disponível em: <http://www.naturezaonline.com.br/natureza/conteudo/pdf/09 _TerraVRetal_4852.pdf>. Acesso em: 20 ago. 2013.

TOLEDO, L. G., NICOLELLA, G. Índice de qualidade de água em microbacia sob uso agrícola e urbano. Scientia Agrícola, vol 59, n. 1, 2004. 